\title{
Editorial
}

\section{Editorial: What Makes Young Surgeons Tick (or Cut)?}

\author{
Seth S. Leopold MD
}

T $\mathrm{n}$ the next couple of months, this year's class of residents and fellows will graduate. These surgeons go out into the world with many incentives to operate, and very few reasons not to. On the receiving end, practices and hospitals place few if any restrictions on these surgeons, many of whom will operate with no oversight at all after graduation-apart from the diffuse and distant specter of the oral boards process in the United States and analogous quizzes elsewhere. While these examinations likely filter out some of the more-

The author certifies that he, or any members of his immediate family, has no commercial associations (eg, consultancies, stock ownership, equity interest, patent/licensing arrangements, etc) that might pose a conflict of interest in connection with the submitted article.

All ICMJE Conflict of Interest Forms for authors and Clinical Orthopaedics and Related Research ${ }^{\circledR}$ editors and board members are on file with the publication and can be viewed on request.

The opinions expressed are those of the writers, and do not reflect the opinion or policy of CORR ${ }^{\circledR}$ or the Association of Bone and Joint Surgeons ${ }^{\circledR}$.

S. S. Leopold MD ( $\square)$

Clinical Orthopaedics and Related

Research, Philadelphia, PA 19103, USA

e-mail: sleopold@clinorthop.org severe outliers in terms of knowledge, skill, and judgment, they have little or no ability to establish or enforce the kinds of normative standards that would make us proud to be surgeons, and they probably are not the right tool for that job, anyway. That responsibility instead should fall to practice groups, senior partners, and (for surgeons who are employed by medical centers), hospitals.

Many factors push young surgeons towards the knife. Among them:

(1) Most surgeons get paid to operate. Although many young surgeons start out on salary, the financial incentive to become a full partner or to enter an incentive-based arrangement is strong.

(2) Even in settings where there is no such incentive-based arrangement, one of the deepest values surgeons share is that of hard work; young surgeons want to validate the idea that their partners hired a hard worker, and there are few clearer ways to demonstrate "hard work" than through collections or relative value units (RVUs).

(3) Recent graduates want to "grow up" already; their college classmates have been in the working world taking responsibility for their decisions for a decade or more by the time our graduates first practice independently. Medical school and residency can feel infantilizing; at the very least, they delay an individual's transition to full responsibility by a period of years. These surgeons feel ready, at long last, to surge.

(4) They are not rheumatologists; in principle, they are in the business because they like to operate.

(5) If they do not recommend surgery, someone else might. I am surprised by how often I hear this as a justification to operate in borderline clinical situations, as well as some that are beyond the border entirely.

(6) They have seen tough problems solved during residency and fellowship, and perhaps they have even solved a few. But they have yet to be stung (nor have they yet stung a patient) through bad calls or bad technique, and they may not yet really own the idea that they ever will. Youthful enthusiasm, an asset in so many other spheres, can be a terrible liability here.

Pushing surgeons towards a nonoperative approach are such factors as ... 


\section{Editorial}

No, I cannot think of any, either. At least none large enough to tip the balance against the earlier list.

This is where senior partners need to come in. Remind the new hires that healing always involves more than surgery, and that sometimes healing is better achieved without it. Reassure them that their practices will build, and that it is better for them, for their patients, and for the reputation of the group if the build is deliberate and thoughtful. Finally, reinforce the idea that the default treatment for many elective orthopaedic conditions (and many urgent ones) can and should be nonoperative management. Augusto Sarmiento MD, a past president of the American Academy of Orthopaedic Surgeons, has made a career of studying clinically reasonable alternatives to surgery, and to pointing out what he perceives to be our excessive enthusiasm for surgical treatments [911]. Despite his efforts, one indeed wonders whether the problem is getting worse rather than better; certainly there have been probing analyses of large datasets by others [5] suggesting strongly that factors apart from clinical necessity can influence surgical decision-making.

As such, the thoughtful practice group needs to offer more than talk to its new recruits. Incenting the desired behavior is critical to achieving and sustaining it. Practice-group leaders with integrity have employed creative approaches involving close oversight and progressive independence for new surgeons taking on increasingly challenging procedures, and they have done this even in resource-poor settings [4]. But because that is not practical or possible in all locations, consider other incentives. Rather than evaluating new partners solely by RVUs or collections, perhaps keep tabs on the proportion of patients presenting for elective surgery while taking narcotic analgesics $[7,8,15]$, or who have identifiable and modifiable comorbidities like incompletely controlled anxiety or depression [1, 3, 7, $12,13]$, all of which have been associated with persistent pain, disability, and dissatisfaction after elective surgery. For patients presenting with common conditions, consider tracking adherence to generally accepted practice guidelines, which can make our surgical interventions safer [2, 14], yet are only inconsistently followed [6, 14]. If these particular incentives are not a good fit, at the very least discuss and articulate the group's core values in explicit and measurable ways, and ask the following question: What, apart from dollars or RVUs, can we track to ensure that new surgeons' practices reflect our normative standards?

After you have done so, please share your good ideas with us in a letter to the editor (EIC@ clinorthop.org).

Acknowledgments I would like to thank Lee Beadling BA and Mark C. Gebhardt MD for their thoughtful suggestions, which improved this essay.

\section{References}

1. Bot AG, Menendez ME, Neuhaus V, Ring D. The influence of psychiatric comorbidity on perioperative outcomes after shoulder arthroplasty. $J$ Shoulder Elbow Surg. 2014;23:51927.

2. DeSancho MT, Bardarova S, Chapin J. Adherence to guidelines for perioperative management of anticoagulation results in decreased bleeding complications: A single-centre experience. [Published online ahead of print February 15, 2015]. Blood Coagul Fibrinolysis. DOI: 10.1097/ MBC.0000000000000275.

3. Judge A, Arden NK, Cooper C, Kassim Javaid M, Carr AJ, Field RE, Dieppe PA. Predictors of outcomes of total knee replacement surgery. Rheumatology (Oxford). 2012;51: 1804-1813.

4. Leopold SS. Editorial: Transition from training to practice - Is there a better way? Clin Orthop Relat Res. 2014:472;1351-1352.

5. Martin BI, Franklin GM, Deyo RA, Wickizer TM, Lurie JD, Mirza SK. How do coverage policies influence practice patterns, safety, and cost of initial lumbar fusion surgery? A population-based comparison of 
workers' compensation systems. Spine J. 2014;14:1237-1246.

6. Matzon JL, Lutsky KF, Maloney M, Beredjiklian PK. Adherence to the AAOS upper-extremity clinical practice guidelines. Orthopedics. 2013;36:e1407-1411.

7. Nota SP, Spit SA, Voskuyl T, Bot AG, Hageman MG, Ring D. Opioid use, satisfaction, and pain intensity after orthopedic surgery. Psychosomatics. 2014; Epub ahead of print.

8. Pivec R, Issa K, Naziri Q, Kapadia BH, Bonutti PM, Mont MA. Opioid use prior to total hip arthroplasty leads to worse clinical Outcomes. Int Orthop. 2014;38:1159-1165.
9. Sarmiento A. Staying the course. $J$ Bone Joint Surg Am. 1991;73:479483.

10. Sarmiento A, Latta LL. Fractures of the middle third of the tibia treated with a functional brace. Clin Orthop Relat Res. 2008;466:31083115.

11. Sarmiento A, Latta LL. The evolution of functional bracing of fractures. Bone Joint J. 2006;88:141-148.

12. Utrillas-Compaired A, De la TorreEscuredo BJ, Tebar-Martínez AJ, Asúnsolo-Del Barco Á. Does preoperative psychologic distress influence pain, function, and quality of life after TKA? Clin Orthop Relat Res. 2014;472:2457-2465.
13. Wylde V, Dixon S, Blom AW. The Role of preoperative self-efficacy in predicting outcome after total knee replacement. Musculoskeletal Care. 2012;10:110-118.

14. Young B, Ng TM, Teng C, Ang B, Tai HY, Lye DC. Nonconcordance with surgical site infection prevention guidelines and rates of surgical site infections for general surgical, neurological, and orthopaedic procedures. Antimicrob Agents Chemother. 2011;55:4659-4663.

15. Zywiel MG, Stroh DA, Lee SY, Bonutti PM, Mont MA. Chronic opioid use prior to total knee arthroplasty. J Bone Joint Surg Am. 2011;93:1988-1993. 